\title{
PENGARUH PENDEKATAN VALUE CLARIFICATION TECHNIQUE (VCT) METODE PERCONTOHAN TERHADAP HASIL BELAJAR PKn SISWA SD
}

\author{
Diana Novita Sari Nst ${ }^{1)}$, Reinita ${ }^{2)}$, Mansur Lubis ${ }^{3)}$ \\ ${ }^{1)}$ Mahasiswa Universitas Negeri Padang, Indonesia \\ ${ }^{2}$ Pembimbing 1, Universitas Negeri Padang, Indonesia \\ ${ }^{3}$ Pembimbing 2, Universitas Negeri Padang, Indonesia \\ ${ }^{1)}$ diananovitasari.nst95@gmail.com, ${ }^{2)}$ reinita reinita@yahoo.com, ${ }^{3)}$ mansurlubis1954@yahoo.co.id
}

\begin{abstract}
ABSTRAK
Penelitian ini bertujuan untuk mengetahui pengaruh penggunaan pendekatan Value Clarification Technique (VCT) metode percontohan terhadap hasil belajar siswa pada pembelajaran $\mathrm{PKn}$. Jenis penelitian ini adalah quasi eksperimen design dengan bentuk nonequivalen control group design. Penelitian ini dilakukan di SDN 13 Cingkariang Kec.Banuhampu Kab.Agam pada kelas VA sebagai kelas eksperimen dan VB sebagai kelas kontrol yang masing-masing berjumlah 25 siswa. Teknik analisis data menggunakan uji normalitas dan uji homogenitas selanjutnya dilakukan uji-t untuk melihat pengaruh pedekatan VCT. Berdasarkan hasil penelitian diperoleh rata-rata nilai pretest sebesar 38,768 untuk kelas eksperimen dan 41,448 untuk kelas kontrol. Rata-rata nilai posttest sebesar 90,68 untuk kelas eksperimen dan sebesar 86,32 untuk kelas kontrol. Berdasarkan perhitungan uji-t diperoleh $t_{\text {hitung }}$ sebesar 1,73 sedangkan $t_{\text {tabel }}$ pada taraf signifikan 0,05 adalah sebesar 1,67722, sehingga $t_{\text {hitung }}>t_{\text {tabel }}$. Dengan demikian disimpulkan bahwa penggunaan pendekatan VCT metode percontohan berpengaruh terhadap hasil belajar PKn siswa di kelas V SDN 13 Cingkariang.
\end{abstract}

Kata Kunci : Pendekatan Value Clarification Technique (VCT) metode percontohan, Hasil Belajar Siswa, PKn

\section{THE EFFECT OF VALUE CLARIFICATION TECHNIQUE (VCT) MODELING METHOD ON THE STUDENTS' LEARNING OUTCOME IN CIVIC EDUCATION}

\begin{abstract}
This study aims to determine the effect of Value Clarification Technique (VCT) modeling method on the studnts' learning outcome in civic education. This study is a quasi-experimental design with a non-equivalent control group. The research was conducted in elementary school Number 13 Cingkariang Banuhampu Sub-district of Agam District with class VA as the experimental class and Class VB as the control class. Both classes have twenty five students. The data analysis technique employed was the normality test and homogeneity test, which was then followed by a t-test to see the effect of VCT. The results show that the average pretest score is 38,768 for the experimental class and 41,488 for the control class. The average posstest score is 90,68 for the experimental class and 86,32 for the control class. The result of the t-test shows that the $t_{\text {count }}$ is 1,73 and the $t_{\text {table }}$ on the significance level of 0,05 is 1,6772, which means that $t_{\text {count }}>t_{\text {table. }}$. Therefore, it is concluded that the Value Clarification Technique modeling method affects the students' learning outcome in civic education in Elementary School Number 13 Cingkariang.
\end{abstract}

Keyword: The Value Clarification Technique (VCT) Modeling Method, Students' Learning Outcome, Civic Education. 


\section{PENDAHULUAN}

Pendekatan pembelajaran merupakan titik tolak atau sudut pandang kita terhadap proses belajar mulai dari awal sampai akhir pembelajaran sehingga tujuan pembelajaran dapat tercapai dengan baik. Hal ini sejalan dengan pendapat Taufik dan Muhammadi (2011:39) yang menyatakan bahwa "Pendekatan pembelajaran merupakan titik tolak atau sudut pandang kita terhadap proses pembelajaran, yang merujuk pada pandangan tentang terjadinya suatu proses yang sifatnya masih sangat umum, di dalamnya mewadahi, menginsiprasi, menguatkan, dan melatari metode pembelajaran dengan cakupan teoretis tertentu".

Pendekatan pembelajaran menjadi hal yang paling penting dalam proses belajar mengajar di kelas. Guru harus bisa mencocokkan pendekatan dengan materi pembelajaran agar siswa lebih mudah memahaminya. Salah satu pendekatan yang mudah untuk dipahami siswa dalam proses pembelajaran yaitu pendekatan Value Clarification Technique (VCT).

Pendekatan pembelajaran VCT merupakan suatu pendekatan inovatif yang menekankan nilai/sikap sosial, budaya, personal, dan masyarakat. Adisusilo (2012:141) mengemukakakn bahwa "VCT merupakan pendekatan pendidikan nilai dimana peserta didik dilatih untuk menemukan, memilih, menganalisis, memutuskan, dan mengambil sikap sendiri nilai-nilai hidup yang ingin diperjuangkannya." Peserta didik dibantu menjernihkan, memperjelas atau mengklarifikasikan nilai-nilai hidupnya lewat value problem solving, diskusi, dialog dan presentasi. Misalnya peserta didik dibantu menyadari nilai hidup mana yang sebaiknya diutamakan dan dilaksanakan.

VCT juga memberi penekanan pada usaha membantu siswa dalam mengkaji perasaan dan perbuatan untuk meningkatkan kesadaran tentang nilai-nilai mereka sendiri. Pendekatan VCT memiliki beberapa bentuk, salah satu bentuk dari pendekatan VCT adalah VCT Percontohan.

Menurut Ahmad (dalam jurnal Reinita, 2012:152) pendekatan VCT metode percontohan merupakan "model VCT yang berupaya mengungkapkan nilai/sikap melalui contoh-contoh, cerita dan kasus sebagai media stimulus. Cerita dan kasus yang digunakan harus mampu menyeret perasaan dan kejiwaan siswa dan menyentuh hati nurani siswa yang pada akhirnya akan melahirkan argumen dan klarifikasi pendirian siswa”.

Reinita dalam jurnalnya (2012:152) menyatakan bahwa "dengan penggunaan pendekatan pembelajaran VCT Percontohan, guru dapat memberikan pemahaman pengetahuan, pembinaan sikap, dan melatih berprilaku melalui percontohan dari guru serta pengalaman langsung siswa”.

Pendekatan VCT metode percontohan ini sangat sesuai dengan konsep pembelajaran PKn yang menitikberatkan pada penanaman nilai, sikap, norma, dan moral. Pembelajaran PKn merupakan salah satu mata pembelajaran yang dipelajari oleh siswa di Sekolah Dasar (SD) yang menekankan pada pembentukan 
nilai, sikap dan perilaku siswa agar menjadi warga negara yang baik serta melaksanakan hak dan kewajiban sebagai warga negara.

Melalui pembelajaran PKn di SD diharapkan kepada siswa agar benar-benar dapat memahami, menghayati, dan mengamalkan dalam bentuk perilaku seharihari, baik sebagai individu, maupun anggota masyarakat. Apabila hal tersebut terlaksana dengan baik tentunya akan memudahkan membentuk siswa yang memiliki kemampuan berfikir kritis, rasional, beriman, dan memiliki sikap peduli terhadap negaranya.

Hal tersebut sejalan dengan kurikulum BSNP Peraturan menteri pendidikan nasional No 22 Tahun 2006 menyatakan bahwa tujuan mata pembelajaran PKn adalah agar siswa memiliki kemampuan : (1) Berpikir secara aktif, rasional, dan kreatif dalam menanggapi isu kewarganegaraan (2) Berpartisipasi secara aktif dan bertanggung jawab, dan bertindak secara cerdas dalam kegiatan kemasyarakatan, berbangsa dan bernegara serta anti korupsi (3) Berkembang secara positif dan demokrasi untuk membentuk diri berdasarkan karakterkarakter masyarakat Indonesia agar dapat hidup bersama dengan bangsa-bangsa lainnya (4) Berinteraksi dengan bangsa-bangsa lain dalam peraturan dunia secara langsung atau tidak langsung dengan memanfatkan teknologi informasi dan komunikasi.

Melalaui pendekatan pembelajaran VCT metode percontohan, siswa akan belajar PKn dalam konteks pengalaman nyata, yang meliputi aplikasi keterampilan berfikir, memecahkan masalah, apresiasi budaya, apresiasi nilai moral (Putra, 2014:2). Maka 3| P a g e denganpendekatan VCT metode percontohan ini pembelajaran PKn akan lebih bermakna dalam kehidupan sehari-hari serta dapat meningkatkan hasil belajar PKn siswa di sekolah. Oleh sebab itu, pedekatan VCT percontohan ini sangat baik dan cocok sekali digunakan dalam pembelajaran PKn terutama pada penanaman nilai, sikap dan perilaku peserta didik.

Berdasarkan observasi yang dilakukan penelitipada tanggal 16 Juli 2018 di kelas V SDN 13 Cingkariang Kec.Banuhampu Kab.Agam diketahui bahwa pelaksanaan proses pembelajaran PKn secara umum masih cenderung menggunakan model konvensional. Menurut Djamarah (dalam Isjoni 2007 : 25) "Model pembelajaran konvensional adalah model pembelajaran tradisional atau disebut juga dengan model ceramah, karena sejak dulu model ini telah dipergunakan sebagai alat komunikasi lisan antara guru dengan anak didik dalam proses belajar dan pembelajaran".

Model pembelajaran konvensional yang banyak digunakan didalam kelas adalah dengan metode ceramah, dimanasaat pelaksanaannya guru lebih aktif dan lebih dominan dalam menjelaskan materi secara lisan dan tanya jawab . Kemudian di SD yang telah penelitiobservasi terlihat bahwa pada saat proses pembelajaran PKn masih kurangnya penggunaan media pembelajaran sehingga membuat siswa menjadi pasif dan jenuh dalam mengikuti proses pembelajaran di kelas.

Selain dari permasalahan di atas, pada saat proses pembelajaran PKn guru kurang menstimulus pikiran dan perasaan serta kurang mengarahkan siswa dalam menentukan 
nilai/sikap yang akan dipilih dalam kehidupan sehari-hari. Hal ini memiliki pengaruh terhadap rendahnya hasil belajar PKn siswa di kelas V SDN 13 Cingkariang Kec.Banuhampu Kab.Agam.

\section{METODE PENELITIAN}

Penelitian ini merupakan jenis penelitian kuantitatif, dimana data yang dikumpulkan berupa angka-angka dengan analisis data menggunakan statistik. Menurut Sugiyono (2012:34) "Penelitian kuantitatif digunakan apabila peneliti ingin mengetahui pengaruh atau traeatment tertentu terhadap suatu permasalahan". Jenis metode penelitian yang akan digunakan adalah penelitian eksperimen.

Penelitian ini menggunakan desain penelitian eksperimen yaitu quasi eskperimental design. Quasi eksperimen design mempunyai kelompok kontrol, tetapi tidak dapat berfungsi sepenuhnya mengontrol variabel-variabel luar yang mempengaruhi pelaksanaan eksperimen. Dalam penelitian ini akan digunakan desain quasi eksperimen bentuk nonequivalent control group design, yaitu desain eksperimen quasi yang menggunakan pretes sebelum diberikan perlakukan dan posttest setelah dilakukan perlakuan. Populasi dalam penelitian ini yaitu seluruh siswa kelas V SDN 13 Cingkariang Kec.Banuhampu Kab.Agam.

Dalam penelitian ini, sampel diambil menggunakan teknik non probability sampling yaitu dengan jenis Purposive Sampling. Menurut Yusuf (2007:205) menjelaskan bahwa "Purposive Sampling merupakan teknik penentuan sampel dimana sampel ditentukan berdasarkan pertimbangan-pertimbangan atau kriteria yang telah ditetapkan terlebih dahulu." Adapun kriteria/dasar pertimbangan yang dibuat peneliti dalam penentuan sampel ini adalah sebagai berikut:

a. Peneliti menggunakan sekolah yang masih menggunakan kurikulum KTSP.

b. Pretest diberikan kepada kedua kelas yaitu kelas VA dan VB SDN 13 Cingkariang. Setelah didapatkan hasil pre-test dari kedua kelas, dilakukan uji homogenitas dan normalitas. Hasilnya menunjukkan bahwa kelas VA dan VB normal dan homogen.

c. Berdasarkan data primer yang didapatkan di SDN 13 Cingkariang, jumlah siswa kelas V sebanyak 51 siswa yaitu kelas VA berjumlah 26 siswa dan kelas VB berjumlah 25 siswa. Oleh karena itu peneliti akan menyamakan jumlah siswa yang akan dijadikan sampel sehingga sampel yang diambil pada penelitian ini berjumlah 50 siswa yaitu kelas VA berjumlah 25 siswa dan kelas VB berjumlah 25 siswa dan cara mengeluarkan siswa yang tidak akan dijadikan sampel yaitu dengan menggunakan sistem undian sehingga terpilihlah siswa kelas $\mathrm{V}$ A yang bernomor absen 8 untuk tidak dijadikan sampel.

d. Jumlah jenis kelamin siswa pada tiap kelas sama, yaitu kelas VA jumlah lakilaki sebanyak 14 orang dan perempuan sebanyak 11 orang, kelas VB jumlah laki-laki sebanyak 14 orang dan perempuan sebanyak 11 orang. 
Untuk menentukan kelas eksperimen dan kelas kontrol yaitu dengan melakukan undian karena cara undian dapat dilakukan apabila jumlah anggota sampel sedikit (Heryanto, 2014:16), setelah melakukan undian terpilih kelas VA sebagai kelas eksperimen (kelompok yang mendapatkan perlakuan berupa pembelajaran dengan menggunakan pendekatan VCT metode percontohan) dan kelas VB sebagai kelas control (kelompok yang tidak mendapatkan perlakuan atau melaksanakan pembelajaran secara konvensional, sebagaimana biasanya guru melaksanakan pembelajaran).

\section{HASIL DAN PEMBAHASAN}

1. Deskripsi Data Kelas Eksperimen dan Kontrol

a. Data pretest kelas eksperimen dan kontrol

Data pretest diperoleh dari tes awal sebelum diberikan pembelajaran dengan pendekatan Value Clarification Technique (VCT) metode percontohan,dan siswa kelas kontrol menggunakan model konvensional. Niai Pre-test kelas eksperimen dan kelas kontrol dapat dilihat pada tabel 1 , berikut :

Tabel 1 Hasil pretest kelas eksperimen

\begin{tabular}{lcc}
\hline \multicolumn{1}{c}{ Deskripsi } & $\begin{array}{c}\text { Hasil Pretest } \\
\text { Kelas } \\
\text { Eksperimen }\end{array}$ & $\begin{array}{c}\text { Hasil Pretest } \\
\text { Kelas Kontrol }\end{array}$ \\
N & 25 & 25 \\
Nilai & 62,7 & 72,6 \\
maksimun & & \\
Nilai & 23,1 & 26,4 \\
minimum & 39,6 & 46,2 \\
Rentang & 7 & 8 \\
Panjang kelas & 6 & 6 \\
Banyak kelas & 6 \\
\hline
\end{tabular}

Dari table 1 di atas diketahui bahwa pada kelas eksperimen dan kelas kontrol sama-sama memiliki jumlah siswa sebannyak 25 orang. Nilai pretest maksimum kelas eksperimen lebih rendah dari kelas kontrol dengan selisish 9,9. Selanjutnyanilai minimum pretest kelas eksperimen lebih rendah dari kelas kontrol dengan selisih 3,3. Kemudian rentang kelas eksperimen 39,6 sedangkan rentang kelas kontrol 46,2. Panjang kelas eksperimen 7 sedangkan panjang kelas kontrol 8 dengan selisih 1 . Dan banyak kelas eksperimen dan banyak kelas kontrol sama-sama 6 .

b. Data Postest Kelas Eksperimen dan kontrol

Data postest diperoleh dari hasil tes akhir setelah diberikan pembelajaran menggunakan pendekatan Value Clarification Technique (VCT) metode percontohan pada kelas eksperimen dan model konvensional pada kelas kontrol. Nilai postest kelas eksperimen dan kelas kontrol dapat dilihat pada tabel 2, berikut: 
Tabel 2 Hasil postest kelas eksperimen dan kelas kontrol

\begin{tabular}{|l|c|c|}
\hline Deskripsi & $\begin{array}{c}\text { Hasil } \\
\text { Postest } \\
\text { Kelas } \\
\text { Eksperimen }\end{array}$ & $\begin{array}{c}\text { Hasil Postest } \\
\text { Kelas Kontrol }\end{array}$ \\
\hline $\mathrm{N}$ & 25 & 25 \\
\hline $\begin{array}{l}\text { Nilai } \\
\text { maksimun }\end{array}$ & 100 & 100 \\
\hline $\begin{array}{l}\text { Nilai } \\
\text { minimum }\end{array}$ & 76 & 72 \\
\hline Rentang & 24 & 28 \\
\hline $\begin{array}{l}\text { Panjang } \\
\text { kelas }\end{array}$ & 4 & 5 \\
\hline $\begin{array}{l}\text { Banyak } \\
\text { kelas }\end{array}$ & 6 & 6 \\
\hline
\end{tabular}

Dari tabel 2, di atas diketahui bahwa pada kelas eksperimen dan kelas kontrol sama-sama memiliki jumlah siswa sebannyak 25 orang. Nilai maksimum postest kelas eksperimen dan kelas kontrol samasama memiliki nilai100. Selanjutnya nilai minimum postest kelas eksperimen lebih tinggi dari kelas kontrol dengan selisih 4 . Kemudian rentang kelas eksperimen 24 sedangkan rentang kelas kontrol 28. Panjang kelas eksperimen 4 sedangkan panjang kelas kontrol 5 dengan selisih 1 . Serta banyak kelas eksperimen dan banyak kelas kontrol sama-sama 6.

2. Pengujian Prasyarat Analisis dan Pengujian Hipotesis

a. Uji Normalitas

Uji normalitas dalam penelitian ini menggunakan uji Liliefors dengan berbantu Microsoft Excel 2007 dengan taraf signifikansi $5 \%$ atau $\alpha=0,05$.

1) Normalitas pretest kelas eksperimen dan kelas kontrol

Tabel 3, Hasil Uji Normalitas Pretest Kelas Eksperimen dan Kontrol

\begin{tabular}{|c|c|c|c|c|c|}
\hline No & Sampel & $\begin{array}{c}\mathrm{N} \\
\text { (banyak } \\
\text { siswa) }\end{array}$ & $\begin{array}{c}\mathrm{L} \\
\text { hitung }\end{array}$ & $\begin{array}{c}\mathrm{L} \\
\text { tabel } \\
\alpha \\
0,05\end{array}$ & $\begin{array}{c}\text { Hasil } \\
\text { Perhitun } \\
\text { gan }\end{array}$ \\
\hline 1 & $\begin{array}{c}\text { Kelas } \\
\text { Eksperi } \\
\text { men }\end{array}$ & 25 & $\begin{array}{c}0,0320 \\
2\end{array}$ & $\begin{array}{c}0 \\
1772\end{array}$ & Normal \\
\hline 2 & $\begin{array}{c}\text { Kelas } \\
\text { Kontrol }\end{array}$ & 25 & $\begin{array}{c}0,0114 \\
5\end{array}$ & $\begin{array}{c}0, \\
1772\end{array}$ & Normal \\
\hline
\end{tabular}

Berdasarkan tabel 5, diketahui $\mathrm{L}$ hitung kelas eksperimen sebesar 0,03202 dan Lhitung kelas kontrol sebesar 0,01145 dengan jumlah sampel masing-masing 25 orang. Pada taraf signifikansi $\alpha=0,05$ didapat nilai $\mathrm{L}$ tabel sebesar 0, 1772. Sehingga pada kelas eksperimen diperoleh L hitung < L tabel, $(0,03202<0,1772)$, dan untuk kelas kontrol juga diperoleh L hitung $<\mathrm{L}$ tabel $(0,01145<0,1772)$. Dengan demikian, dapat disimpulkan bahwa data pada kedua kelas berdistribusi normal.

2) Normalitas postest kelas eksperimen dan kelas kontrol

Tabel 4, Hasil Uji Normalitas Postest Kelas Eksperimen dan Kontrol

\begin{tabular}{|c|c|c|c|c|c|}
\hline $\begin{array}{l}\mathrm{N} \\
\mathrm{O}\end{array}$ & Sampel & $\begin{array}{c}\mathrm{N} \\
\text { (ban } \\
\text { yak } \\
\text { sisw } \\
\text { a) } \\
\end{array}$ & $\begin{array}{c}\mathrm{L} \\
\text { hitung }\end{array}$ & $\begin{array}{c}\mathrm{L} \\
\text { tabel } \\
\alpha \\
0,05\end{array}$ & $\begin{array}{c}\text { Hasil } \\
\text { Perhitu } \\
\text { ngan }\end{array}$ \\
\hline 1 & $\begin{array}{c}\text { Kelas } \\
\text { Eksperi } \\
\text { men }\end{array}$ & 25 & $\begin{array}{c}0,0193 \\
48\end{array}$ & $\begin{array}{c}0, \\
1772\end{array}$ & Normal \\
\hline 2 & $\begin{array}{c}\text { Kelas } \\
\text { Kontrol }\end{array}$ & 25 & $\begin{array}{c}0,0383 \\
44\end{array}$ & $\begin{array}{c}0, \\
1772\end{array}$ & Normal \\
\hline
\end{tabular}


Berdasarkan table 4, diketahui L hitung kelas eksperimen sebesar 0,019348 dan L hitung kelas kontrol sebesar 0,038344 dengan jumlah sampel masing-masing 25 orang. Pada taraf signifikansi $\alpha=0,05$ didapat nilai L tabel sebesar 0, 1772. Sehingga pada kelas eksperimen diperoleh L hitung < L tabel, (0,019348<0,1772), dan untuk kelas kontrol juga diperoleh Lhitung<Ltabel $\quad(0,038344<0,1772)$. Dengan demikian, dapat disimpulkan bahwa data pada kedua kelas berdistribusi normal.

b. Uji Homogenitas

Uji homogenitas dalam penelitian ini dilakukan untuk mengetahui apakah data untuk kelas eksperimen dan kelas kontrol memiliki varian yang homogen atau tidak. Uji homogenitas dalam penelitian ini dilakukan dengan menggunakan uji-F berbantu Microsoft Excel 2007 dengan taraf signifikansi $5 \%$ atau $\alpha=0,05$.

1) Homogenitas pretest kelas eksperimen dan kelas control

Tabel 5 Hasil Uji Homogenitas Pretest Kelas Eksperimen dan Kontrol

\begin{tabular}{|c|c|c|c|c|c|c|}
\hline No & Sampel & $\mathrm{N}$ & $\begin{array}{c}\text { Var } \\
\text { ians } \\
\mathrm{i}\end{array}$ & $\begin{array}{c}\text { F } \\
\text { hitu } \\
\text { ng }\end{array}$ & $\begin{array}{c}\mathrm{F} \\
\mathrm{tab} \\
\mathrm{el} \\
\alpha \\
0,0 \\
5\end{array}$ & $\begin{array}{l}\text { Hasil } \\
\text { Peng } \\
\text { ujian }\end{array}$ \\
\hline 1 & $\begin{array}{c}\text { Kelas } \\
\text { Eksperi } \\
\text { men }\end{array}$ & 25 & $\begin{array}{c}153 \\
, 59 \\
5 \\
\end{array}$ & \multirow[t]{2}{*}{$\begin{array}{c}1,1 \\
7\end{array}$} & \multirow{2}{*}{$\begin{array}{l}1,9 \\
8\end{array}$} & \multirow{2}{*}{$\begin{array}{l}\text { Hom } \\
\text { ogen }\end{array}$} \\
\hline 2 & $\begin{array}{c}\text { Kelas } \\
\text { Kontrol }\end{array}$ & 25 & $\begin{array}{c}180 \\
, 66 \\
5\end{array}$ & & & \\
\hline
\end{tabular}

Berdasarkan tabel 5, diketahui Fhitung kelas eksperimen dan kelas kontrol sebesar 1,17 dengan jumlah sampel masing-masing 25 orang. Pada taraf signifikansi $\alpha=0,05$ didapat Ftabel 1,98. Sehingga diperoleh Fhitung < Ftabel, yakni $(1,17<1,98)$. Dengan demikian, dapat disimpulkan bahwa data pada kelas eksperimen dan kelas kontrol memiliki varian yang homogen.

2) Homogenitas postest kelas eksperimen dan kelas kontrol

Tabel 6 Hasil Uji Homogenitas Postest Kelas Eksperimen dan Kontrol

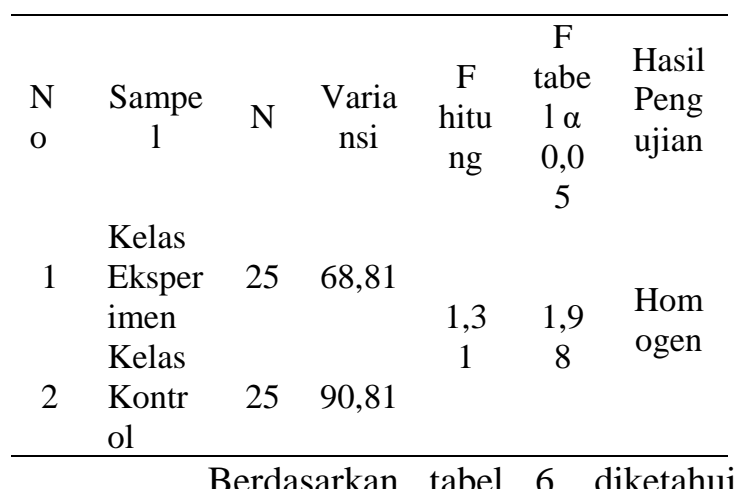

Fhitung kelas eksperimen dan kelas kontrol sebesar 1,31 dengan jumlah sampel masing-masing 25 orang. Pada taraf signifikansi $\alpha=0,05$ didapat Ftabel 1,98. Sehingga diperoleh Fhitung < Ftabel, yakni $(1,31<1,98)$. Dengan demikian, dapat disimpulkan bahwa data pada kelas eksperimen dan kelas kontrol memiliki varian yang homogen.

c. Uji Hipotesis

Uji hipotesis dilakukan terhadap nilai postest kelas eksperimen dan kelas kontrol. Berdasarkan uji 
prasyarat analisis data, diketahui bahwa data postest untuk kedua kelompok berdistribusi normal dan memiliki varian yang homogen. Sehingga dapat dilakukan pengujian hipotesis dengan menggunakan uji $\mathrm{t}$ separated variance.

Tabel 7 Hasil Uji-t Postest Kelas Eksperimen dan Kelas Kontrol

\begin{tabular}{|c|c|c|c|c|c|c|}
\hline $\begin{array}{l}\mathbf{N} \\
\mathbf{0}\end{array}$ & Data & $\begin{array}{c}\text { Rata- } \\
\text { rata }\end{array}$ & $\begin{array}{c}\text { Varia } \\
\text { nsi }\end{array}$ & $\begin{array}{c}\text { t } \\
\text { hitu } \\
\text { ng }\end{array}$ & $\begin{array}{c}\mathrm{t} \\
\text { tab } \\
\text { el } \\
\alpha \\
0,05\end{array}$ & $\begin{array}{l}\text { Hasil } \\
\text { Peng } \\
\text { ujian }\end{array}$ \\
\hline 1 & $\begin{array}{l}\text { Ekspe } \\
\text { rimen }\end{array}$ & 90,68 & 68,81 & \multirow{2}{*}{1,73} & \multirow{2}{*}{$\begin{array}{l}1,67 \\
722\end{array}$} & \multirow{2}{*}{$\begin{array}{c}\text { Hipot } \\
\text { esis } \\
\text { diteri } \\
\text { ma }\end{array}$} \\
\hline 2 & $\begin{array}{c}\text { Kontr } \\
\text { ol }\end{array}$ & 86,32 & 90,81 & & & \\
\hline
\end{tabular}

Berdasarkan tabel 7, diketahui nilai $\mathrm{t}$ hitung sebesar 1,73 dan $\mathrm{t}$ tabel 1,67722 pada taraf signifikasi $\alpha=0,05$. Karena 1,73>1,67722 maka Ho ditolak, dan Ha diterima (ada pengaruh penggunaan pendekatan Value Clarification Technique (VCT) metode percontohan pada Pembelajaran PKn di Kelas V SDN 13 Cingkariang.

Pretest atau tes awal yang dilakukan di kelas eksperimen diperoleh rata-rata 38,768 dengan nilai tertinggi 62,7 dan nilai terendah 23,1 serta data pretest berdistribusi normal. Sementara Postest atau tes akhir digunakan untuk mengukur sejauh mana kemampuan peserta didik setelah diberikan perlakuan. Hasil postest di kelas eksperimen diperoleh rata-rata 90,68 dengan nilai tertinggi 100 dan nilai terendah 76 serta data berdistribusi normal.
Sejalan dengan data kelas eksperimen di atas, tes awal pada kelas kontrol diperoleh rata-rata 41,448 dengan nilai tertinggi 72,6 dan nilai terendah 26,4 serta data berdistribusi normal. Sementara Postest atau tes akhir digunakan untuk mengukur sejauh mana kemampuan peserta didik setelah diberikan perlakuan. Berdasarkan hasil postest di kelas kontrol diperoleh ratarata 86,32 dengan nilai tertinggi 100 dan terendah 72 serta data berdistribusi normal.

Data pretest kelas eksperimen dan kelas kontrol terbukti berdistribusi normal. Selanjutnya dilakukan Uji homogenitas menggunakan uji Hartley dengan ketentuan jika nilai signifikansinya $\mathrm{F} \quad(\max )_{\text {hitung }} \leq$ $\mathrm{F}(\max )_{\text {tabel }}$ maka dapat dikatakan varian data sama yang dilakukan terhadap hasil pretest kelas eksperimen dan kelas control. Hasil F hitung sebesar 1,17 sedangkan $\mathrm{F}$ tabel pada taraf signifikansi 1,98. Dengan demikian dapat disimpulkan bahwa data pretest kedua kelas memiliki variansi yang homogen.

Uji Hartley juga dilakukan terhadap data posttest kedua kelas, berdasarkan hasil pengujian postes kelas eksperimen dan kelas kontrol diperoleh $F$ hitung sebesar 1,31 sedangkan $F$ tabel pada taraf signifikansi 1,98. Jadi dapat disimpulkan Fhitung < Ftabel yang berarti data postest kedua kelas memiliki variansi yang homogen. 
Selanjutnya pengujian hipotesis pada penelitian ini dilakukan dengan Uji-t separated variance dikarenakan hasil data kelas eksperimen dan kelas kontrol berdistribusi normal dan homogen. Berdasarkan pengujian diperoleh hasil nilai $\mathrm{t}_{\text {hitung }}>$ dari $\mathrm{t}_{\text {tabel}}$, yaitu $1,73>$ 1,67722 sehingga Ho ditolak dan $\mathrm{Ha}$ diterima, sehingga dapat disimpulkan bahwa penelitian ini dapat memberikan pengaruh yang signifikan terhadap hasil belajar siswa.

\section{SIMPULAN}

1. Berdasarkan analisis data dari penelitian serta pengujian hipotesis yang dilakukan dapat disimpulkan bahwa Pendekatan Value Clarification Technique (VCT) metode percontohan memiliki pengaruh yang signifikan terhadap hasil belajar PKn siswa di Kelas V SDN 13 Cingkariang Kec.Banuhampu Kab.Agam khususnya pada KD 1.3 Menunjukkan Contohcontoh perilaku dalam menjaga keutuhan NKRI.

2. Hasil analisis data pretest, kelas eksperimen memperoleh rata-rata 38,768 dan pada kelas kontrol diperoleh rata-rata 41,448. Dengan demikian dari data pretest kedua kelas diketahui bahwa rata-rata kelas kontrol lebih besar dari rata-rata kelas eksperimen dengan selisih 2,68.

3. Hasil analisis data posttest, nilai rata-rata kelas eksperimen yang menggunakan pendekatan Value Calrification Technique (VCT) metode percontohan memperoleh nilai rata-rata 90,68 dan kelas kontrol yang menggunakan pembelajaran konvensional memperoleh nilai rata 86,32. Jadi rata-rata nilai kelas eksperimen lebih tinggi dari pada kelas kontrol dengan selisih nilai 4,36.

4. Hasil uji hipotesis didapat bahwa $t_{\text {hitung }}>$ $\mathrm{t}_{\text {tabel}}$, yaitu 1,73>1,67722 yang dibuktikan dengan taraf signifikan $\alpha \quad 0,05$ yang berarti terdapat pengaruh yang signifikan pada pendekatan Value Calrification Technique (VCT) metode percontohan terhadap hasil belajar peserta didik pada pembelajaran PKn di kelas V SDN 13 Cingkariang Kec.Banuhampu Kab.Agam.

\section{DAFTAR RUJUKAN}

Adisusilo, Sutarjo. 2012. Pembelajaran NilaiKarakter Konstrutivisme dan VCT sebagai Inovasi Pendekatan Pembelajaran Afektif. Jakarta: PT Rajagrafindo Persada.

Isjoni. 2007. Paradigma Pembelajaran Bermakna. Pekanbaru: Falah Production.

Putra, Dewa Made Arta. 2014. Vol.2 No.1 Pengaruh Model Pembelajaran Value Clarification Technique (VCT) Terhadap Hasil Belajar PKn Siswa Kelas V.

Reinita. 2012. Vol.XII No.1. Peningkatan Proses Pembelajaran PKN Melalui Penggunaan Pendekatan Pembelajaran Nilai Di Kelas II sekolah Dasar Pembangunan UNP.

Sudjana,Nana. 2010. Penilaian Hasil Proses Belajar Mengajar. Bandung: PT Remaja Rosdakarya

Sugiyono. 2012. Metode Penelitian Pendidikan Pendekatan Kuantitatif, Kualitatif, dan $R \& D$. Bandung: Alfabeta.

Taufik, Muhammadi. 2011. Mozaik Pembelajaran Inovatif. Padang: Sukabina Press. 